\title{
Interpretive description: a viable methodological approach for nursing research
}

\author{
Descrição interpretativa: uma abordagem metodológica viável para a pesquisa em enfermagem \\ Descripción interpretativa: un enfoque metodológico viable para la investigación en enfermedad
}

\author{
Ilara Parente Pinheiro Teodoro ${ }^{1}$ (c) \\ Vitória de Cássia Félix Rebouças ${ }^{1}$ \\ Sally Elizabeth Thorne ${ }^{2}$ \\ Naanda Kaana Matos de Souza ${ }^{1}$ \\ Lídia Samantha Alves de Brito ${ }^{1}$ \\ Ana Maria Parente Garcia Alencar ${ }^{1}$
}

1. Universidade Regional do Cariri.

Crato, CE, Brasil.

2. University of British Columbia.

Vancouver, Canadá.

\section{Abstract}

Objective: To present a theoretical reflection about the origin and the assumptions of the "Interpretive Description" method, and to discuss its applicability in Nursing and Health research. Method: Theoretical-reflective study, based on articles and books published by proponent of this approach, as well as scientific articles in which the authors reported having used this method in their studies. Results: It was evidenced that the "Interpretive Description" arose from the need to generate a better understanding of clinical practices in Nursing. This approach has its roots in the methodological traditions of the Social Sciences, although it differs from them in terms of its excessive rigidity and essentially theoretical objectives. The proposed method has been applied in several studies either in Nursing as other areas of Health. Conclusion: The "Interpretive Description" is considered a feasible approach for the production of knowledge in Applied Sciences such as Nursing.

Keywords: Nursing research; Qualitative research; Methods; Research projects; Nursing.

\section{Resumo}

Objetivo: Apresentar reflexão teórica sobre o método de "Descrição Interpretativa", discutindo sua aplicabilidade às pesquisas em Enfermagem e em Saúde. Método: Estudo teórico-reflexivo, com base em artigos e livros publicados pela proponente dessa abordagem, e em artigos nos quais os autores referiram ter usado o método. Resultados: Evidenciou-se que a "Descrição Interpretativa" surgiu da necessidade de uma opção metodológica mais direcionada às Ciências Aplicadas como a Enfermagem. Essa abordagem tem raizes em tradições metodológicas das Ciências Sociais, mas diferencia-se destas por sua natureza mais prática e pela maior flexibilidade na aplicação das etapas do método. Esse referencial metodológico vem sendo aplicado em estudos tanto de Enfermagem como de outras áreas da Saúde. Conclusão: Considera-se a "Descrição Interpretativa" uma abordagem metodológica viável e exequível para a produção de conhecimento em Enfermagem.

Palavras-chave: Pesquisa em enfermagem; Pesquisa qualitativa; Métodos; Projetos de pesquisa; Enfermagem.

\section{Resumen}

Objetivo: Presentar una reflexión teórica sobre el origen y los presupuestos del método de "Descripción Interpretativa", y discutir su aplicabilidad en las investigaciones en Enfermería y Salud. Método: Estudio teórico-reflexivo, teniendo como base artículos y libros publicados por la proponente de este enfoque, así como artículos científicos en los que los autores mencionar on haber usado ese método en sus estudios. Resultados: Se evidenció que la "Descripción Interpretativa" surgió de la necesidad de generar un mejor entendimiento de prácticas clínicas en Enfermería. Este enfoque tiene raíces en las tradiciones metodológicas de las Ciencias Sociales, aunque diferenciándose de éstas en lo que concierne a su excesiva rigidez y objetivos de naturaleza esencialmente teórica. El método propuesto ha sido aplicado en varios estudios tanto de Enfermería y de otras áreas de la Salud. Conclusión: Se considera la "Descripción Interpretativa" una borda je viable para la producción de conocimiento en Ciencias Aplicadas como la Enfermería.

Palabras clave: Investigación en enfermería; Investigación cualitativa; Métodos; Proyectos de investigación; Enfermería.
Corresponding author:

Vitória de Cássia Félix Rebouças.

E-mail: vitoria.felix@urca.br

Submitted on 09/22/2017.

Accepted on 01/17/2018.

DOI: 10.1590/2177-9465-EAN-2017-0287 


\section{INTRODUCTION}

The importance and necessity of the use of theoretical and methodological references to support qualitative research in the area of Nursing has been emphasized in order to add scientificity and quality to the studies, aspects that have been debated and highlighted since the end of the last century. ${ }^{1}$ Many of these references - such as Phenomenology, Data Based Theory and Ethnography - come from other fields of knowledge, evidencing, thus, the need of Nursing to invest in the elaboration of references that can explain the specificities of knowledge production in this area. $^{2}$

In this context, a Canadian researcher from University of British Columbia (UBC), assisted by graduate students from the same institution, proposed a methodological referential for the development of nursing research - also applicable to other areas of Health - which the author calls "Interpretive Description".2,3

The "Interpretive Description" is an analytical, inductive approach designed to create ways of understanding human health and aspects related to the experience of a disease that have consequences for the clinical context and practice in Health and which are of interest for Nursing researchers. ${ }^{3}$ It stands out as a qualitative research method capable of generating reliable and meaningful disciplinary knowledge, allowing the evolution of the qualitative methodological application in the scope of Nursing. This referential has been used as a basis to support several Nursing studies in an international context. . $^{4-9}$

However, analyzing the main national nursing journals, it is well known that this referential is still unexplored in researches developed by Brazilian nurses. Therefore, the purpose was to present a theoretical reflection about the origin and the assumptions of the "Interpretive Description" method, and to discuss its applicability in Nursing and Health research.

It is believed that this discussion can contribute to the dissemination of new methods that will support research in Nursing and, thus, increase the possibilities regarding the production of knowledge, facilitating the expansion and development of research techniques beyond conventional approaches.

\section{METHOD CREATION AND DEFINITIONS}

The "Interpretive Description" can be understood as a method that provides a methodological direction to researchers of Applied Sciences, such as Nursing, to lead the elaboration of research questions focused on practical aspects of these areas of knowledge, as well as, entry into the field in a logical, systematic and justified manner, and the creation of a data analysis so that the researcher's engagement with the data makes possible an interpretation of the studied context beyond the obvious. ${ }^{2}$
To understand the need to create the method, it is necessary, initially, to rescue some aspects related to the emergence of qualitative research in the context of Nursing. By the 1980 s, nursing researchers started, through qualitative nature research, to explore new possibilities of knowledge production in addition to the quantitative researches long used in Health Sciences. For this reason, these researchers were guided by the formal methodological tradition coming from the Social Sciences, as a way to give greater credibility to the knowledge produced in their studies, in a fully oriented environment for the biomedical model. ${ }^{10}$

Therefore, most of the traditional qualitative research in Health derives methodologically from the Social Sciences, especially from the methods proposed by Anthropology, Sociology and Psychology. The problem in adapting methods of the Social Sciences to Health research is that, although the Social Sciences scholars can research aspects oriented to practical situations, the origins and characteristics of these areas of knowledge are solidly directed and grounded for the understanding of problems of a more theoretical rather than practical problems. Thus, when methods used in social sciences are applied to health research, its goal, therefore, is not to solve problems of the daily life of people in their health-disease process, but rather to respond to problems of a more elemental nature with an understanding of, for example, how social groups behave and what constitutes the nature of human experience. ${ }^{2}$

If on the one hand, the qualitative approaches derived from other disciplines did not always meet the specific demands of Nursing researchers, ${ }^{3}$ on the other, quantitative scientific approaches were insufficient to answer all the theoretical and practical questions of Nursing, despite the initial appeal of the qualitative methodology of the Social Sciences and its immediate adoption as a foundation for qualitative research in Nursing, the orthodoxy of research techniques proposed by social scientists over time proved to be incongruent with the pragmatism, objective and characteristics unique to the search for knowledge of Nursing. ${ }^{11}$

It is in view of this scenario that the "Interpretive Description" method arose, starting from the need for a qualitative research approach capable of generating a better understanding of situations that occur in the contexts in which health practice develops and, thus, responding to needs in the scope of Nursing science, enabling the development of knowledge to support clinical practice. The method was presented as a way of trying to answer complex questions related to the health-disease process that are relevant to both Nursing and other health disciplines, but which are not readily answered by traditional qualitative methodologies. ${ }^{2}$

Studies for the development of this method began in the late 1990s, when Sally Elizabeth Thorne and two graduate 
students published an article entitled "Interpretive Description: a non-qualitative alternative for developing nursing knowledge", 3 a methodological manuscript original for an audience of nursing scholars on the need for an alternative to conventional qualitative approaches to Health research. Later, Sally Thorne presented the method in a more in-depth and detailed way in a book called "Interpretive Description - qualitative research for applied practice", ${ }^{2}$ already in its second edition. ${ }^{2}$

The author is a professor and researcher at the University of British Columbia - School of Nursing, Vancouver, Canada. Her researches have been directed to the study of chronic diseases, especially, to questions related to the experiences of people with cancer.

In the proponent's understanding of the method, when the components of a qualitative research project are directed by nursing disciplinary epistemology, this provides a highly effective theoretical framework for designing applied clinical studies, ensuring that the researcher will follow a logical line of reasoning nature and structure of knowledge of practice. ${ }^{2}$ For Thorne, ${ }^{10}$ the role of the researcher in the "Interpretive Description" will always be delineated by the need of his reality for the generation of new knowledge, and it is up to the researcher to combine the understanding of what is known with authentic desire of new possibilities in the structuring of knowledge, which may change the way the situation analyzed was interpreted.

The usefulness of this method has been recognized by scholars from several areas of health, and it is possible to verify the applicability of this reference in investigations, both in Nursing and in other disciplines, as will be detailed in this article. As Thorne points out, ${ }^{10}$ within the context of human variation, this method helps guide nurses as well as other health professionals to contextualize diseases in the experiential, spiritual, sociocultural, and geopolitical worlds of human life.

To follow the steps of the "Interpretive Description", it is necessary to generate questions in the clinical field for which the available knowledge is still not enough, to carry out a review of the literature with the intention of knowing and drawing conclusions about the "state of the art" in relation to the clinical problem and frame a study project using strategies for a reliable study to then enter the field, at which point the analysis is already starting. This analysis performed repeatedly, according to Thorne, ${ }^{10}$ allows the researcher's mind to weigh, challenge, evaluate, and fragment pieces of data until they can be formed into parts that seem to inform something individually and collectively of what was not previously known about the phenomenon.

This method provides a basis for identifying patterns between data, or "conceptual links", when one tries to locate something more intimate within a general context, or even the subjectivity of the researcher's experience within a commonly understood reality. ${ }^{2}$
This research approach proposes to create a rich and detailed description of some phenomenon, discovering associations, relations and patterns that help the reader to understand deeper, more complete and richer aspects, to link them in a way that produces a better understanding of the phenomenon, triggering a vision and an action related to practice. ${ }^{2}$

In applying the method, the researcher describes a phenomenon by placing it in its context, with all its nuances and influences, without, however, intending to provide an explanatory model for it. The overall reliability of data from studies using this method is reinforced by the application of multiple strategies to address credibility, reliability, and transferability. Using constant comparative methods, researchers and participants "co-construct" an orderly, coherent, and persuasive narrative that can support clinical practice.

\section{"INTERPRETIVE DESCRIPTION" AND THE REFERENCES OF ETHNOGRAPHY, DATA-BASED THEORY AND PHENOMENOLOGY}

The "Interpretive Description" is a method that has roots in Phenomenology, Ethnography, and Data-based Theory. ${ }^{2}$ In this way, it uses methodological tools common to these methods. However, when the "Interpretive Description" uses these tools, it is concerned that their use is not to overly theorize the results, but to offer practical solutions to the problems that the health professions present.

While each of these disciplinary traditions has a role to play in the larger space of ideas, none of these approaches alone is compatible with the pragmatic requirements of applied disciplines, since they remain firmly based on theoretical rather than practical problems. ${ }^{2}$

Thus, the "Interpretive Description" is directed to researches in Applied Sciences - particularly to Nursing - while at the same time seeking to distance itself from Social Sciences, assuming that the method used in these Sciences would not produce results applicable to clinical practice. In the author's perception, this is justified considering that nurses gather large quantities of practical knowledge that are tested and validated in the patient's daily experience, which would differentiate them from social researchers, who tend to see the practical problems as an additional occasion to theorize; and health professionals, specifically nurses, use theory as a way to provide answers to solve real-world problems.

In fact, some objectives that are central to a particular method of the Social Sciences are not always goals to be sought by nurses in the production of knowledge that subsidizes their performance. To make this statement clear, one can cite Ethnography, which has a way of extracting information through interviews and observation, and that could be considered of interest to Nursing 
researchers. However, Ethnography's objective of broadly interpreting the cultural context of a given reality would hardly be of interest to nurses seeking answers to practical research questions. ${ }^{11}$

The author adds that although there is already a wide range of methods coming from the Social Sciences and that can be used by Nursing researchers, when these methods are used non-critically and only to faithfully respect the methodological assumptions of the technique or approach adopted, less useful results can be produced to the needs of the Nursing area. Thus, "Interpretive Description" may be an option in the sense of going beyond the inflexibility and theoretical orientation found in some traditional Social Science research methods. ${ }^{11}$

\section{APPLICATION OF THE METHOD IN NURSING RESEARCH AND HEALTH DISCIPLINES}

With a view to understanding how the assumptions and stages of the "Interpretive Description" have been applied, some studies are presented below that used it as a methodological guide, highlighting aspects such as the context in which such studies applied the method and questions methodologies of a practical nature, such as sample size, selection of participants, instruments and techniques used to collect data, and how studies report the data analysis process. In exemplifying the use of the method with the following articles, it is sought to offer subsidies to help, in a practical way, researchers who intend to apply this methodological approach to the development of their research.

In articles that have used this methodological reference, it can be seen that this approach can be applied to several areas belonging to the Health Sciences. Among the selected papers to highlight the application of the "Interpretive Description", here allusion is made to studies in the area of Nursing and research in the fields of Health knowledge, which are presented as other possible areas of application of this approach.

Of the studies that used the method in the area of Nursing, are reported researches that have turned to the study of the perceptions and experience of patients, family and health professionals in the most diverse contexts, such as studies directed to the analysis of the experience of the parents of children with asthma; ${ }^{7}$ of the caregivers of migrant patients; ${ }^{4}$ of parental traumas associated to premature birth; ${ }^{5}$ of premature menopause induced by chemotherapy: ${ }^{12}$ of communication in shared decision-making in cancer patients; ${ }^{13}$ of public health nurses in home visits with vulnerable young mothers; ${ }^{14}$ and the communication needs throughout the cancer trajectory from the perspective of the patients themselves. ${ }^{15}$

Regarding research using the method and that were directed at other health areas, it is also perceived that the research topics investigated involve a diverse range of topics, such as those related to patients' preferences for the behaviors of physicians during the communication of end of life; 6 to beliefs, experiences and attitudes related to evidence-based practice in clinical physiotherapy education; ${ }^{16}$ to the experiences of young adolescents in relation to physical activity practice; ${ }^{8}$ as well as some studies that have explored and understood the experiences of people with mental illness and addictions in community pharmacies; ${ }^{9}$ and the perspectives of physiotherapists about preparing for work in private practice. ${ }^{17}$

Another aspect to be highlighted in relation to the practical application of the "Interpretive Description" refers to the number and forms of selection of participants in research that use this reference. In this respect, Thorne ${ }^{2}$ considers that the sample may be of several sizes, although the great majority of studies within this approach are susceptible to the formation of relatively small sample groups (between five and 30 participants). It is through the deep involvement with a small number of individuals familiar with the researcher and willing to share their experiences that, according to the author, it is possible to produce something worthy of documenting.

The appropriate sample size for research developed in this methodological approach should be defined in alignment with the nature of the phenomenon under study, just as it will depend on the interpretation of the state of science related to the clinical circumstance studied and the expected level of theoretical development that the study aims to achieve. To do this, the researcher must understand what is known, making a relation between the size of the sample and the types of interpretations that can be made based on it. ${ }^{10}$

In the studies that here exemplify the use of this method, the samples ranged from six to 32 participants. However, it is also possible, depending on the specific characteristics of the research, to have a much larger sample size, as in a study developed by Thorne et al. ${ }^{13}$ which presented a sample composed of 60 participants. In this study, the researchers presented results from a court in which the changes in the needs and perceptions of cancer patients were analyzed in relation to the communication, during several phases of the disease trajectory.

In the definition of the methodological path of any investigation there is, besides the concern with the size of the sample, the attention on the part of the researchers in defining the way in which the participants of the study will be selected. Regarding this point, the "Interpretive Description" does not establish a single form or rigid procedures for obtaining the sample group of a research. As Thorne ${ }^{2}$ says, the notion of representation and understanding about working sample size and deciding on sampling procedures are inherent parts of all research plans and indicates that, like other qualitative research methods, when using "Interpretive Description" the usual sampling techniques are convenience sampling, theoretical and intentional saturation, noting that, regardless of the technique used, the important thing is for the researcher to maintain an integrity of interpretation according to the limits and the possibilities that the selected sample and the nature of the sampling technique actually permit. ${ }^{18}$ 
The freedom to use different participant recruitment techniques is quite evident when we analyze some studies that have applied the "Interpretive Description" as a methodological guide. In some of these studies the researchers chose to use intentional sampling for sample selection. ${ }^{5,7,16}$ In this strategy, the researcher seeks to identify, in advance, the main groupings or conditions of individuals that can contribute significantly to the objectives of the study. ${ }^{2}$

In other studies, ${ }^{6,17}$ there is a reference to the use of theoretical saturation sampling, which Thorne ${ }^{2,3}$ reports as a form of sample selection that occurs continuously, with the refinement of demographic variables or phenomena, in an attempt to find the maximum variation of information about it, adding variables that would not appear before entering the study. Even though it points to theoretical saturation as a sampling technique that can be employed, the author ${ }^{2}$ alerts to the challenges inherent in its use, especially when it is considered that patients can present an infinite variation in their experiences regarding health care, recognizing that "outleirs" - that is, those individuals with characteristics quite different from the others in a group - may exist.

Also in relation to the sample selection form and to exemplify the use of convenience sampling, we can cite the study by Murphy ${ }^{9}$ that used this technique for the recruitment of people with experience of mental illnesses and addictions. Regarding the use of this type of sampling, although it is in the list of techniques pointed out by Thorne, ${ }^{2}$ the samples by convenience can create a strong base for the "description". However, this type of sampling tends to create, proportionally, greater challenges to justify interpretation.

Regarding the data collection process, when adopting the "Interpretive Description" as a methodological reference, the researcher can use multiple and diverse approaches to data collection, being emphasized the individual interview, considered in the "Interpretive Description" - and reiterating other already established methods - as a pillar in qualitative research in general, and specifically in Nursing, since it contains a large amount of contextual information and a background of significance for the study participant, which, in principle, may not be totally relevant to the purposes of the study but which, throughout the analytical process, can be presented as fundamental for a more dense and expressive interpretation. ${ }^{17}$ Depending on the way the interview is constructed, this technique of data collection can be used both in cross-sectional studies, and in longitudinal studies. ${ }^{10,18}$

In the articles in which the method is applied, the importance that the interview has in the process of obtaining the data is well-known, with due adjustments to the investigated object and the characteristics of the research participants. In the application of the interview, for example, the average length of time varied from 20 minutes to two and a half hours and it was observed that the researchers used this technique of data collection in different ways, as in the studies of Abdul-Razzak et al. ${ }^{6}$ and Kalengayi et al., ${ }^{4}$ whose interviews consisted of only one open-ended question, asking the participants to share any relevant experiences associated with the subject under investigation, so that throughout the process the interview guide would be refined based on issues and emerging observations. Or, the semi-structured interview script, from the study by Archibald et al., ${ }^{7}$ which was prepared based on a literature review and designed to capture data that fit the objectives. The way of applying the interview is also very variable, although it is perceived a tendency of the researchers to realize it only in a single moment, although this is not a rule imposed by the "Interpretive Description". As an example, we can mention the study by Clark et al., ${ }^{8}$ in which the data were collected through two moments, the initial interview being more exploratory and the second interview guided by the insights, concepts and themes that emerged in the first set; and the study of Thorne et al., ${ }^{13}$ in which, after the initial interview, that was slightly oriented according to a set of preliminary questions to establish a common basis, the interview process continued bimonthly in person or by telephone.

In order to leverage the information provided by the interview and to assist the analytical process, Thorne ${ }^{2}$ stresses the importance of getting and providing feedback from the participants in relation to the information collected, as it will provide another opportunity for participants to "co-create" the study's findings. This is observed, for example, in the study by Clark et al., ${ }^{8}$ in which, in the second moment of interviews, the main investigator shared some of the first results in order to obtain feedback to advance and refine the analysis. In the Brisbois' study, ${ }^{12}$ after the final review of the theme, three participants received a summary of the results by e-mail, for feedback. And the study by Atkinson and McElroy ${ }^{17}$ in which participants had the opportunity to modify their transcriptions to promote data reliability and encourage further reflection and insight after the interview.

In addition to the interview, other forms of data collection, such as data collection in focus groups, participant observation, and documentary analysis may be used. What is important is that the researcher make combinations of appropriate approaches in order to achieve better understanding, without relying on the limits inherent in any single approach. The researcher may also use alternative data sources (patient records, published testimonials, among others) that may have a huge value for the primary material and should not be neglected. ${ }^{10,18}$

In relation to the focus groups, Thorne ${ }^{2}$ emphasizes that they can be a good strategy, which allows discovering or creating shared perspectives, as a powerful tool for public opinion or social conscience building, instead of focusing solely on individual differences. Some papers using the methodological approach proposed by Thorne report the use of focus groups, ${ }^{9,14}$ such as the study by Dmytryshyn et al., ${ }^{14}$ which used focus groups in the first stage of data collection, as a way of directing the aspects to be deepened during interviews stage. 
Regarding participant observation - which represents the opportunity to enter the field, observe and participate in many encounters in the research environment, making a series of key observations - the author points out that a significant advantage of this technique is that it allows the researcher to operate from a point of view that is not overly influenced by subjectivity. Thus, the task of the participant observer is to systematically ensure that the "lens" through which the researcher is operating is open, transparent and clear, and the quality of his research product will depend entirely on how convincing the researcher will be able to expose. ${ }^{2}$

Within the context of articles reporting the use of the "Interpretive Description", the study by Kalengayi et al., ${ }^{4}$ reported having collected data through participant observation associated with the interview.

Another point to highlight in relation to data collection is that several researchers use specific techniques, such as triangulation of data sources, to increase credibility within an "Interpretive Description" study, ${ }^{2}$ as Olsen et al., ${ }^{16}$ who, in contrast to the individual interviews - in which the unique aspects of each participant's experience were analyzed in depth and in context - the focus group session created a mechanism by which analytical standards and conclusions could be generated from the synthesized data to be validated, clarified or refined through the group discussion.

Still in relation to the collection, Thorne ${ }^{2}$ guides the registration, in a "blank notebook", from the context of all the episodes of data collection, linking these contexts to the phenomena under study. This allows the researcher to ask questions among the cases, noting emerging patterns that one wishes to follow, which arouses the researcher's critical reflection, disciplining the continuous interpretive challenge. Such field notes are independent of the collection techniques or instruments used and may assist the researcher as he collects data and later helps him to contextualize such data in the analysis process.

In studies using the "Interpretive Description", 4,6-9,14,17 the researchers mentioned using field notes to capture the observations made during the interviews and the contexts in which they occurred, such as reactions and nonverbal language, and annotations of emerging themes, also functioning as a reflective diary to capture changes of ideas or personal responses to the ongoing research.

On the analytical process, the methodological approach proposed by Thorne ${ }^{2,18}$ can be said to be characterized by an agile and continuous relationship between data collection and analysis, with each iteratively subsidizing the other. Interviews are recorded and transcribed literally; and the field notes taken to capture the observations made during interviews help to contextualize the data during the analysis, helping to maintain the integrity of the participants' stories and consistency throughout the comparative process. ${ }^{2}$
In the early stages of analysis, the researcher is encouraged to focus on seizing broad issues of the overall picture, that is, seizing what is being developed within the data context, rather than looking only at the minutiae of the data, which could make the study limited. ${ }^{2,3}$ At this stage, it is important to focus on questions such as "What is going on here?" and "What are we learning about it?" in an effort to move from the particular to the whole. ${ }^{5}$ Thorne ${ }^{2}$ points out that questions like these will stimulate more coherent analytical frameworks for "Interpretive Description" by combining large numbers of small data units. This will allow a better relationship of each case from which relevant themes will emerge throughout the analysis of the data, articulating a holistic understanding about the phenomenon under study.

To increase the validity of the results, all transcribed data must be read in detail several times to develop a sense of the whole beyond the immediate impression of what they contain. Thus, it is possible to obtain a comprehensive view of the data to consider similarities and differences in relation to a wide range of dimensions between the different interviews. ${ }^{2}$ Olsen et al. ${ }^{16}$ corroborate with the author when they point out that through this exercise it is possible to compare and contrast both within and between the interviews, making possible to generate patterns and themes within the data set. Based on this activity, one can evaluate the need to modify the interview guide for the next meeting, since the initial analytical assumptions are sought in the data collection in progress.

In this sense, the analysis process becomes challenging, and the researcher must immerse himself in the data insofar as there is a strategic need for comparisons and objective and subjective combinations between the information, to know them and to apprehend them in a satisfactory way, in order to propose various ways to order and organize them. By following these steps, it is possible to ensure that the final result points to the best possible representation of the phenomena in question. ${ }^{18}$

Various tools and techniques can be helpful in making data work easier. Encoding can support this process, but you should never master it. The researcher must have the ongoing ability to interrogate the data with increasing levels of understanding and questioning, so early coding may impede this process. ${ }^{10}$ Examples include studies by Lasiuk et al., ${ }^{5}$ and Olsen et al., ${ }^{16}$ who, after identifying themes, performed open coding, where each significant segment of the text received a conceptual code to classify and organize the information in a manageable way. It should be noted, however, that these themes are provisional and researchers are open to modifying or deleting them as the process is developed, unlike the coding categories used, for example, in Quantitative Content Analysis.

As the codes become saturated, we move to the coding of patterns, at which point the codes are refined and the specific dimensions of the experiences will be grouped into recurring 
themes. ${ }^{5}$ Through this, Thorne ${ }^{2}$ points out that it is possible to create a description rich and detailed understanding of some phenomenon in a way that helps the reader understand deeper, more complete, and richer aspects.

As the last aspect to be approached in relation to the analysis, it should be pointed out that, according to Thorne, ${ }^{2}$ in this procedure the researcher can use tools like software that can be of great help in the process of data management, and that are highly favorable to the organization and classification, by removing conventional manual organization work. Some of the studies used a qualitative software management system (NVivo) that supports the classification and presentation of data for analysis. $7,9,13,14,16,17,19$ However, Thorne ${ }^{2}$ emphasizes that these programs do not lead to inductive analysis and thus those who have no experience with their use should use these features with caution.

Considering the aspects discussed in this topic, with examples that illustrate how the "Interpretive Description" method has been applied in practice, it is possible to verify that it has been accepted in the academic environment as a methodological resource to guide the research. It is believed that this fact can be attributed to the clear and practical nature as to how the method is presented and because a methodological approach is not established with steps too rigid, since in all texts where the method is presented, it is the author's option to propose a research approach that, although prized for quality, is focused on the real world of research in applied knowledge areas.

\section{CONCLUSIONS}

Considering the aspects discussed here, it can be concluded that the "Interpretive Description" has fulfilled its objective of providing a methodological option that may better represent the interests of researchers in Applied Sciences, such as Nursing. Proof of this is the receptivity of researchers who have adopted the method as a guide for the development of their research.

It is considered that the methodological steps proposed by Thorne - here briefly described - are feasible and operable, and can be advocated for its utility and significance as a resource for the production of researches not only in the area of Nursing, but in Health research in general scope.

Despite the enthusiasm in describing this methodological approach, it is never too much to remember that any research method represents only the means by which researchers will produce solutions to their everyday problems, a method that will not be able to reach its full potential without researchers knowing how to ask good research questions, have a critical look at the reality that surrounds them and have the ability to understand and extract in depth the information that the method allows them to obtain.

\section{REFERENCES}

1. Benjumea CC. La calidad de la investigación cualitativa: deevaluarla a lograrla. Texto Contexto Enferm [Internet]. $2015 \mathrm{Jul} / \mathrm{Sep}$; [cited 2018 Feb 23]; 24(3):883-90. Available from: http://www.scielo.br/pdf/tce/v24n3/ es_0104-0707-tce-24-03-00883.pdf

2. Thorne S. Interpretive Description - Qualitative Research for Applied Practice Second Edition ed. New York, London: Routledge; 2016.

3. Thorne S, Kirkham SR, MacDonald-Emes J. Interpretive description: a noncategorical qualitative alternative for developing nursing knowledge. Res Nurs Health 1997;20(2):169-177.

4. Nkulu Kalengayi FK, Hurtig AK, Ahlm C, Ahlberg BM. "It is a challenge to do it the right way": an interpretive description of caregivers' experiences in caring for migrant patients in Northern Sweden. BMC Health Serv Res [Internet]. 2012 Nov; [cited 2018 Feb 23]; 12:433. Available from: https:// www.ncbi.nlm.nih.gov/pubmed/?term $=\% 22$ lt+is+a+challenge+to+do+ it+the+right+way\%22\%3A+an+interpretive+description+of+caregivers '+experiences+in+caring+for+migrant+patients+in+Northern+Sweden

5. Lasiuk GC, Comeau T, Newburn-Cook C. Unexpected: an interpretive description of parental traumas' associated with preterm birth. BMC Pregnancy Childbirth [Internet]. 2013; [cited 2018 Feb 23]; 13 Supp 1:S13. Available from: https://www.ncbi.nlm.nih.gov/pubmed/?term=U nexpected\%3A+an+interpretive+description+of+parental+traumas'+a ssociated+with+preterm+birth

6. Abdul-Razzak A, You J, Sherifali D, Simon J, Brazil K. 'Conditional candour' and 'knowing me': an interpretive description study on patient preferences for physician behaviours during end-of-life communication BMJ Open [Internet]. 2014 Oct; [cited 2018 Feb 23]; 4(10):e005653. Available from: https://www.ncbi.nlm.nih.gov/pubmed/?term='Condit ional+candour'+and+'knowing +me'\%3A+an+interpretive+descriptio $\mathrm{n}+$ study+on+patient+preferences+for+physician+behaviours+during +end-of-life+communication

7. Archibald MM, Caine V, Ali S, Hartling L, Scott SD. What is left unsaid an interpretive description of the information needs of parents of children with asthma. Res Nurs Health [Internet]. 2015 Feb; [cited 2018 Feb 23]; 38(1):19-28. Available from: https://www.ncbi.nlm.nih.gov/pubmed/?ter $\mathrm{m}=$ What+is+left+unsaid $\% 3 \mathrm{~A}+$ an+interpretive+description+of+the+info rmation+needs+of+parents+of+children+with+asthma

8. Clark MI, Spence JC, Holt NL. In the shoes of young adolescent girls: Understanding physical activity experiences through interpretive description. Qualit Res Sport Exerc Health [Internet]. 2011 Oct; [cited 2018 Feb 23]; 3(2):193-210. Available from: http://www.tandfonline.com/ doi/abs/10.1080/2159676X.2011.572180?journalCode=rqrs21

9. Murphy AL, Martin-Misener R, Kutcher SP, O'Reilly CL, Chen TF, Gardner DM. From personal crisis care to convenience shopping: an interpretive description of the experiences of people with mental illness and addictions in community pharmacies. BMC Health Serv Res [Internet] 2016 Oct; [cited 2018 Feb 23]; 16(1):569. Available from: https://www. ncbi.nlm.nih.gov/pubmed/?term=From+personal+crisis+care+to+conv enience+shopping $\% 3 \mathrm{~A}+\mathrm{an}+$ interpretive+description+of+the+experien ces+of+people+with+mental+illness+and+addictions+in+community+ pharmacies

10. Thorne S. Interpretive Description. In: Beck CT, ed. Routledge International Handbook of Qualitative Nursing Research New York: Routledge; 2013. p. 295-306.

11. Thorne S, Stephens J, Truant T. Building qualitative study design using nursing's disciplinary epistemology. J Adv Nurs [Internet]. 2016 Feb; [cited 2018 Feb 23]; 72(2):451-60. Available from: https://www.ncbi.nlm. nih.gov/pubmed/?term=Building+qualitative+study+design+using+nur sing's+disciplinary+epistemology

12. Brisbois MD. An interpretive description of chemotherapy-induced premature menopause among Latinas with breast cancer. Oncol Nurs Forum [Internet]. 2014 Sep; 41(5):E282-9. Available from: https://www. ncbi.nlm.nih.gov/pubmed/?term=An+interpretive+description+of+che motherapy-induced+premature+menopause+among+Latinas+with+b reast+cancer 
13. Thorne S, Oliffe JL, Stajduhar KI. Communicating shared decisionmaking: cancer patient perspectives. Patient Educ Couns [Internet]. 2013 Mar; [cited 2018 Feb 23]; 90(3):291-6. Available from: https:// www.ncbi.nlm.nih.gov/pubmed/22464665

14. Dmytryshyn AL, Jack SM, Ballantyne M, Wahoush O, MacMillan HL. Long-term home visiting with vulnerable young mothers: an interpretive description of the impact on public health nurses. BMC Nurs [Internet]. 2015 Mar; [cited 2018 Feb 23]; 14:12. Available from: https://www.ncbi. nlm.nih.gov/pubmed/?term=Long-term+home+visiting+with+vulnerab le+young+mothers\%3A+an+interpretive+description+of+the+impact+ on+public+health+nurses

15. Thorne S, Oliffe J, Kim-Sing C, Hislop TG, Stajduhar K, Harris SR, et al. Helpful communications during the diagnostic period: an interpretive description of patient preferences. Eur J Cancer Care (Engl) [Internet]. 2010; [cited 2018 Feb 23]; 19(6):746-54. Available from: https://www. ncbi.nlm.nih.gov/pubmed/?term=Helpful+communications+during+th e+diagnostic+period\%3A+an+interpretive+description+of+patient+pr eferences
16. Olsen NR, Bradley P, Lomborg K, Nortvedt MW. Evidence based practice in clinical physiotherapy education: a qualitative interpretive description. BMC Med Educ [Internet]. 2013 Apr; [cited 2018 Feb 23]; 13:52. Available from: https://www.ncbi.nlm.nih.gov/pubmed/?term=E vidence+based+practice+in+clinical+physiotherapy+education $\% 3 \mathrm{~A}+$ a+qualitative+interpretive+description

17. Atkinson R, McElroy T. Preparedness for physiotherapy in private practice: Novices identify key factors in an interpretive description study. Man Ther [Internet]. 2016 Apr; [cited 2018 Feb 23]; 22:116-21. Available from: https://www.ncbi.nlm.nih.gov/pubmed/?term=Prepare dness+for+physiotherapy+in+private+practice $\% 3 \mathrm{~A}+$ Novices+identify + key+factors+in+an+interpretive+description+study

18. Thorne S. Applied Interpretive Approaches. In: Leavy P, ed. The Oxford Handbooks of Qualitative Research. New York: Oxford University Press; 2014. p. 99-115.

19. Maheu C, Thorne S. Receiving inconclusive genetic test results: an interpretive description of the BRCA1/2 experience. Res Nurs Health [Internet]. 2008 Dec; [cited 2018 Feb 23]; 31(6):553-62. Available from: https://www.ncbi.nlm.nih.gov/pubmed/?term=Maheu+C\%2C+Thorne + S.+Receiving+inconclusive+genetic+test+results $\% 3 \mathrm{~A}+$ an+interpreti ve+description+of+the+BRCA $1 \% 2 \mathrm{~F} 2+$ +experience 